\title{
Luandino Vieira: 0 mineiro angolano da memória
}

\author{
Adriana Mello Guimarães ${ }^{1}$
}

RESUMO: Pretendemos neste texto demonstrar que nas "estórias" de Luandino Vieira, ficcionista angolano, o sentido do tempo é vivido em função de suas contradições internas permanentes, que são retratadas pela experiência de vida do autor, descortinada pela memória, conforme expressa os contos A cidade e a infância e Luuanda, e o romance João Vêncio: os seus amores.

ABSTRACT: In this text we intend to show that in the stories by Luandino Vieira, an Angolan fictionist, the inner sense of time occurs in function of its permanent internal contradictions, which are portrayed by the author's life experience, which is unveil by memory, as express the short stories A cidade e a infância and Luuanda, and the novel João Vêncio: os seus amores.

PALAVRAS-CHAVE: Literatura angolana, Luandino Vieira, tempo, memória, infância.

KEYWORDS: Angolan literature, Luandino Vieira; tempo, memory, childhood.

Pode-se assim dizer que do tempo nada se perde porque o passado é presente no presente; ou melhor, o presente não é senão o passado agindo.

(Brito, R. de Farias. O mundo interior, §44)

Quais são os sentimentos, valores e aspirações que emergem quando nos voltamos sobre o nosso vivido mais remoto? Experiência comum aos indivíduos da espécie humana, a vivência da infância só se tornou tema literário com a modernidade. Em À la recherche du temps perdu, como sabemos, o tema foi celebrizado por Proust. Em língua portuguesa, não são poucos os escritores que esse caminho percorreram. Por exemplo, António Nobre assume a memória sob a

\footnotetext{
${ }^{1}$ Mestranda em Estudos Lusófonos da Universidade de Évora, Portugal. Pesquisa: A obra jornalística de Eça de Queirós. E-mail: adriana.mello@netvisao.pt
} 
forma do lirismo: "Mas, hoje, as pombas de oiro, aves da minha infância, / Que me enchiam de Lua o coração, outrora, / Partiram e no Céu evolam-se, à distância!”. Há várias possibilidades de trabalhar o tema. Casimiro de Abreu, expressão do romantismo brasileiro, fala da dor inerente à consciência da transitoriedade e da finitude: "Oh! que saudades que tenho / Da aurora da minha vida / Da minha infância querida/ Que os anos não trazem mais!". Mais recentemente, Dante Milano fala do próprio tempo interno da consciência: "Tempo, vais para trás ou para diante? / O passado carrega a minha vida/ Para trás e eu de mim fiquei distante, / Ou existir é uma contínua ida / E eu me persigo nunca me alcançando? / A hora da despedida é a da partida”.

Cumpre entender, como Agostinho e outros filósofos depois dele, e a exemplo de Bergson e de Husserl, que o tempo da consciência é um fluxo contínuo, uma correnteza em que pulsam simultaneamente o que foi, o que é e o que está vindo a ser. Daí o sentido da memória como modo de presença do que não mais existe; de coisas e de factos vividos que, embora pertencentes ao passado, fazem parte (tanto quanto o fazem as coisas e factos previstos, sonhados, planeados ou apenas imaginados, e que ainda não existem) do mundo real que experimentamos actualmente. Neste sentido, e considerando o contexto da colonização angolana, pretendemos descortinar a vivência da infância de Luandino Vieira - expressa nos contos de A cidade e a infância, nas estórias de Luuanda e no romance João Vêncio: os seus amores, como sendo a fonte e o verdadeiro motor de sua criação literária.

\section{A memória como filão}

Tenho minhas minas para garimpar. (Luandino)

Numa entrevista ao jornal O Globo (17.11.2007), do Rio de Janeiro, Luandino Vieira afirmou que escrever sobre as barreiras de classes e as injustiças é uma opção comprometida com a sua própria vida, "pois essas preocupações constituem uma espécie de aquário onde 
nadam as minhas memórias". Luandino definiu a si mesmo como um escritor que encontrou na memória o seu filão, a sua mina; uma espécie de mineiro do tempo interno da consciência:

Minha ficção sempre se alimentou da memória. É do que se inscreveu na memória que retiro o material que submeto a todos os maus-tratos possíveis até perceber se é válido para justificar meu trabalho sobre ele. Da actualidade conheço pouco. Mas revela-se-me permanente e com persistência o que em minhas memórias de mais de meio século se inscreveu - e não apaga. Tenho minhas minas para garimpar.

Cabe, então, perceber melhor quais são estas memórias no percurso da vida de José Vieira Mateus da Graça, conhecido por Luandino Vieira. Em outra entrevista, ainda no Rio de Janeiro, ${ }^{2}$ ele explicou que o pseudónimo exprime o que foi a progressiva incorporação do seu ser no lugar:

Aos onze anos, eu tinha um jornalzinho manuscrito, e neste jornal eu era o redactor e era o tipógrafo: a minha caligrafia é que constituía o tipo. Eu fazia também uns desenhos para ilustrar as crónicas de futebol, e nestes desenhos eu assinava como Luandino. E também, porque me chamavam de Luandino, devido a minha mania de defender a cidade de Luanda acima de tudo. ${ }^{3}$

De família pobre, Luandino nasceu em Portugal, a 4 de Maio de 1935. Três anos depois, a família foi viver para Angola, colónia portuguesa, onde ele passou a infância e a adolescência. Era a época do Estado Novo, regime autoritário. O que significava Angola no contexto político-económico do Estado Novo? O chefe do governo português, António de Oliveira Salazar, atribuiu aos territórios africanos uma função geográfica estratégica de exploração e de poder. José Freire Antunes resume assim essa época:

Sem surpresa, a África inspiradora de orgulhosa retórica era, nos anos 40 e 50, uma imagem reflexa da matriz ibérica: o Portugal pré-industrial, com um rendimento per capita de 250 dólares (o

\footnotetext{
2 TV Globo, Programa Espaço Aberto, 19.12.2007.

3 Cf Entrevista ao programa Espaço Aberto, dia 19 de Dezembro de 2007. http://video.globo.com
} 
mais baixo da Europa), uma taxa de analfabetismo de 40\%, o mais elevado índice de mortalidade infantil (...) Angola e Moçambique ficaram longamente condenados a baldios do Portugal Europeu. ${ }^{4}$

E o que dizer da ambiência cultural do colono? Um outro escritor, António Cardoso, que compartilhou sua infância com Luandino e foi seu colega, traça um quadro da vida escolar que significa, em poucas palavras, uma formação opressiva: "O liceu era o estabelecimento de ensino mais forte, onde havia o branco de segunda, um ou outro preto, alguns mestiços (...) Professores, angolanos, nunca tivemos nenhum”. ${ }^{5}$ Parece-nos provável que, desde a infância, a formação escolar tenha gerado em Luandino o sentimento do oprimido que liga inexoravelmente o indivíduo ao povo da terra, o que explicaria a sua adopção, por livre escolha, da cidadania angolana.

Ou seja, ao concentrarmo-nos na infância de Luandino, distinguimos uma criança que se torna adulta à força de percorrer um caminho semeado de contradições entre o colonizador e o colonizado; entre o branco e o negro; entre o rico e o pobre. O que o move nesse percurso senão o sentimento de colonizado, de "cópia”, de "postiço", de híbrido? O que o torna criador senão o pensamento dessas contradições e desse sentimento?

\section{Vivência da dor}

Somente a Arte, esculpindo a humana mágoa, Abranda as rochas rígidas, torna água

Todo o fogo telúrico profundo $E$ reduz, sem que, entanto, a desintegre, À condição de uma planície alegre, A aspereza orográfica do mundo!

Provo desta maneira ao mundo odiento Pelas razões do sentimento,

Sem os métodos da abstrusa ciência fria

4 José Freire Antunes, O factor africano 1890-1990, p. 37.

5 Michel Laban, Angola - Encontro com escritores, volume I, pp. 337-339. 
E os trovões gritadores da dialéctica, Que a mais alta expressão da dor estética Consiste essencialmente na alegria. (Augusto dos Anjos, Monólogo de uma Sombra)

A cidade e a infância (contos, 1957), primeiro livro publicado por Luandino, remete o leitor para a década dos anos quarenta, altura do início da formação da identidade nacional angolana. A força e o poder são retratados por dentro, através de imagens do quotidiano. Neste livro, Luandino inicia um percurso de luta contra a injustiça e começa a criar a sua própria linguagem.

O livro chama a atenção das autoridades: afora três exemplares, as autoridades policiais apreenderam toda a edição, inclusive os originais, a composição e as provas. O livro é composto por dez narrativas breves, que descrevem os bairros pobres de Luanda, onde habitam meninos negros, brancos e mestiços. Ouvimos estas vozes como se estivéssemos a escutar alguém a ler em voz alta, e descobrimos dois mundos, um branco e um negro, que vivem na mesma infância. Logo no primeiro conto, Encontro de acaso, somos convidados a entrar na "Grande Floresta" acompanhados por miúdos de oito anos, de "corpos escuros, de brancos que brincavam todo o dia nas areias vermelhas", 6 que saboreavam iguarias como "quicuerra", peixe frito e açúcar preto com "jinguba"; e que queriam conquistar o "Kinaxixi", bairro operário contíguo ao "Makulusu", que era um bairro novo que se ia construindo com o comércio do café. A narrativa recria a desigualdade do sistema colonial. Porém, acima de tudo, introduz a dor como elemento primordial da criação estética:

Como são dolorosas as recordações! Oh, quem me dera outra vez mergulhar o corpo em água suja e ter a alma limpa como nos tempos em que ele, eu, O Mimi, O Fernando Silva, o João Maluco, o Margaret e tantos outros éramos os reis da Grande Floresta. ${ }^{7}$

6 Cf. A cidade e a infância, p. 50.

7 Ibidem. 
O próprio narrador nos conduz a este entendimento, ao confidenciar que "tudo se modificou e só a ferida feita pela memória persiste ainda". ${ }^{8}$ Neste conto estão presentes os valores permanentes internos da consciência e os imperativos históricos e externos da mudança e da transformação - tanto do ser humano como de um povo. Assim, numa sequência de cenas como cinematográficas, a narrativa suscita emoções que envolvem problemas de hoje e de sempre da existência humana.

No segundo conto, $O$ despertar, a nota dominante é o sentido da liberdade. Apesar de a personagem principal se encontrar encarcerada, a detenção física não impede que o seu espírito se mova a procurar com maior intensidade a luz do entendimento e o restabelecimento moral:

A prisão foi para ele de grande utilidade. Nos longos momentos de solidão reviu o que passara e pensou muito. Acusou-se do que tinha culpas. Era a menor parte. E tirou de tudo a grande lição. Foi nessas noites de intensa vigília que readquiriu a confiança em si. E viu que o caminho não estava irremediavelmente escuro. ${ }^{9}$

A vida intelectual surge como um sonho de liberdade, mas esta liberdade não pode ser apenas idealizada. Torna-se necessário enfrentar o sofrimento e construir o futuro: "seguiria e com as mãos pequenas, agora calosas das grades da prisão, trabalharia. Tinha a Vida à sua frente. Tinha mãos para a possuir!”.10

Outro conto de grande impacto é A fronteira de asfalto, que narra a dor do preconceito: é a história de dois jovens, um rapaz negro e uma rapariga branca, Marina e Ricardo, que são proibidos de manter a amizade pela mãe da menina:

- Marina, já não és nenhuma criança para que não compreendas que a tua amizade por esse (...) teu amigo Ricardo não pode continuar. Isso é muito bonito em criança. Duas

\footnotetext{
8 Ibidem.

9Idem, pp. 61-62.

10 Idem, p. 67.
} 
crianças. Mas agora (...) um preto é um preto (...) As minhas amigas todas falam da minha negligência na tua educação. Que te deixei (...) Bem sabes que não é por mim!11

A colocação do asfalto nas ruas delimita a divisão que existia entre dois territórios, entre o bairro branco e o musseque, entre dois mundos, funcionando como símbolo da implementação do sistema colonial e do "progresso". No desfecho do conto, Ricardo, morador do musseque, morre ao tentar entrar em contacto com Marina, a menina de tranças loiras. A interdição do mundo branco ao negro africano e a impossibilidade de diálogo entre universos ideologicamente conflitantes constituem o fio condutor da narrativa.

Os delírios de uma criança doente compõem o conto A cidade e a infância. Zizica é um miúdo loiro que se lembra das mudanças que ocorreram na cidade: "Hoje muitos edifícios foram construídos. As casas de pau a pique e zinco foram substituídas por prédios de ferro e cimento, a areia vermelha coberta pelo asfalto negro e a rua deixou de ser a rua do limão". ${ }^{12}$ No meio das suas memórias, Zizica lembra do dia em que o pai o ensinou a ler a primeira palavra: "guerra". Sonhando, voa num papagaio de seda e canta lenga-lengas típicas do universo lusófono. Neste caleidoscópio de emoções, acompanhamos a morte da melhor amiga, a primeira ida ao cinema, as visitas do médico. Tudo passa, tudo se acaba, ficando da doença, entretanto, a ideia do início da construção de uma identidade própria.

Nos últimos contos do livro, destacamos Faustino. Mais uma vez, ao sentido da dor se incorpora a denúncia do racismo. O conto é belo. A beleza não está na dor, nem na denúncia do racismo, senão no efeito do recurso utilizado para prender a atenção do leitor: a linguagem funciona como elemento potencial de captação estilística e uma espécie de mimetismo ou reprodução da oralidade, que começa da seguinte forma: “Contarei agora a história do Faustino. Não foi a Don'Ana que me

11 Idem, p. 81.

12 Idem, p. 87. 
contou, não senhor", ${ }^{13}$ remetendo o leitor para o ambiente dos antigos contadores de histórias.

Mais do que a evocação de um tempo feliz, mais do que a representação ideológica do vivido, A cidade e a infância exprime a consciência da dor como sendo princípio de criação da obra de arte. Em Luandino, a vivência da dor é matéria-prima de coisas de beleza que nos causam alegria.

\section{A graça e a alegria da estória}

A estória não quer ser história. A estória, em rigor, deve ser contra a História. A estória, às vezes, quer-se um pouco parecida à anedota. (João Guimarães Rosa, Tutaméia, Aletria e Hermenêutica)

O livro Luuanda (1963) é constituído por três "estórias". Aqui Luandino inova no uso da língua, criando uma linguagem que, embora não seja o português falado nos musseques em Luanda, tem esta marca.

Das três "estórias" do livro - Vavó Xixi e seu Neto Zeca Santos, Estória do Ladrão e do Papagaio, Estória da Galinha e do Ovo analisaremos a terceira.

O enredo se desenvolve em torno da luta por um ovo que pode ser visto como um símbolo que representa a identidade dos habitantes de um musseque. Neste texto a infância surge na figura de duas crianças que "traduzem" a fala da natureza, neste caso a galinha. A estória começa "na hora das quatro horas", quando começa a confusão entre duas vizinhas. Nga Zefa tem uma galinha, Cabíri, que insiste em ir alimentar-se no quintal de Nga Bina, uma personagem que, grávida, tem o grande desejo de comer um ovo. Levada pelo desejo, Nga Bina alimenta a galinha, que finalmente põe um ovo em seu quintal. As vizinhas discutem. Uma reclama o direito à propriedade da galinha e do

13 Idem, p. 119. 
ovo; a outra requisita o direito ao ovo enquanto produto da alimentação fornecida em seu quintal. Sem solução à vista, solicitam a mediação da mais velha do grupo, Vavó Bebeca. Nada se resolve; as mulheres, de forma a decidir o caso, pedem ajuda a várias pessoas: a um negociante branco, Sô Zé, que só quer tirar vantagem; ao inteligente seminarista João Pedro; a Sô Vitalino, que explora os pobres mediante o aluguer de cubatas; ao Artur Lemos, ex-notário e bêbado, símbolo da burocracia e da decadência do sistema. Todos tentam conseguir a propriedade do ovo. Entretanto, duas crianças, Beto e Xico, entram em cena, aproximam-se da galinha e, em seguida, afirmam que aprenderam a língua das galinhas. Finalmente, aparece a autoridade policial, e um sargento diz que por não serem autorizadas reuniões com mais de duas pessoas, ele terá de ficar com a galinha e com o ovo da discórdia. Duas são, basicamente, as possibilidades de solução do problema: ou as duas mulheres mantêm o litígio e nenhuma das duas leva o ovo, ou elas se unem para defender o seu direito ao ovo. Neste momento de tensão, as duas crianças, Beto e Xico começam a utilizar a "língua das galinhas" e imitam um galo a chamar pela Cabíri:

Até a Cabíri deixou de se mexer, só a cabeça virava em todos os lados, revirando os olhos a procurar no meio do vento esse cantar conhecido que lhe chamava (...) E, então, sucedeu: Cabíri espetou com força as unhas dela no braço do sargento, arranhou fundo, fez toda a força nas asas, e as pessoas, batendo palmas, uatobando e rindo, fazendo pouco, viram a gorda galinha sair a voar por cima do quintal, direita e leve, com depressa, parecia era ainda um pássaro de voar todas as horas. ${ }^{14}$

A solução, a saída (isto é, a libertação) se dá, evidentemente, pela união dos oprimidos. De facto, Luandino chama a atenção para a necessidade da existência de uma consciência crítica:

O papel de um escritor em qualquer sociedade é ser, realmente, a consciência crítica dessa sociedade (...) Portanto, a consciência crítica seria uma consciência que aponta os erros, as

14 Cf. Luuanda, p. 151. 
dificuldades, os defeitos; tudo quanto, na realidade, deve ser transformado para melhor. ${ }^{15}$

Mas uma significação política da "estória", pura e simples, configuraria apenas uma retórica ideológica; seria uma percepção superficial da dimensão estética da narrativa luandina, porque essa consciência é sempre uma conquista, e começa pela visão crítica de si mesmo como actor da História. Essa consciência outra coisa não é senão o saber contar a própria história como uma anedota, reinventando-a. Ora, isto não é possivel sem uma apropriação da linguagem. O sentido da verdadeira libertação consiste exactamente nisso: o inventar, dentro da História, a própria história, com todos os recursos, com todas as novidades e particularidades que constituem a graça e a alegria anedótica da estória, sem o que não seria uma tarefa suportável.

É o recuperar, urbano, de uma estória tradicional, passada com outros animais. Ou seja: mais uma vez o escritor vai buscar, na memória, as tradições herdadas para consolidar a sua obra singular.

\section{Arquitectura da criação}

Em João Vêncio: os seus amores, Luandino surpreende pela novidade: neste romance ele reúne, num processo de criação particular, a invenção de novas palavras, a destruição de estruturas linguísticas e a infracção das normas sintácticas. Suas estórias descrevem um mundo peculiar, criado, sem dúvida, a partir da memória, mas o próprio autor é impulsionado pelo desejo de uma nova estética em contraposição àquela imposta pelos colonizadores. Assim, o primeiro passo foi tentar romper com a linguagem institucional, subverter a sintaxe e o léxico na busca da reestruturação de uma nova expressividade, mais angolana e menos lusitana. Aqui a dor da infância revela um mundo de caos e destruição, um mundo onde é necessário começar tudo de novo.

\footnotetext{
15 Michel Laban, idem, p. 411.
} 
Pensamos que é neste sentido que devemos entender toda a obra de Luandino. Aqui fica consolidada a herança de múltiplas tradições, que perseguem o autor desde a infância e que se traduz numa obra densa e rica. João Vêncio é o testemunho da descoberta que caminha à procura de uma identidade.

Neste caleidoscópio de emoções e pensamentos, voltamos à infância, aos oito anos da personagem principal. Encontramos um cruzamento de histórias: vizinhas espancadas, reflexões sobre a amizade, a língua, a religião. A "educação de criança tive de mãe e de madrasta", 16 afirma João Vêncio. O pai inicialmente pedreiro, acabou como "industrial da padaria". Mas a maior alegria do nosso protagonista era "encher o coração de ódio",17 furando os olhos aos pássaros e cometendo outras atrocidades.

Escravo das suas paixões, os seus amores desenham uma estrela de três pontas - e todos os amores pertencem às memórias da infância. Só a bailundina está fora. E é justamente a bailundina que João Vêncio tenta estrangular, logo no início da narrativa. Dividido entre vários amores (todos com um uma história trágica à mistura), na constelação amorosa tudo se confunde:

Eu é que sou escravo dos meus amores - a estrela de três pontas com o seu centro dela, a Florinha que não era minha. A Màristrêla e o Mimi, meu só amigo; a menina Tila, asila, doutora, o seu perfume torrado em baixo do céu de veludo, no quente das pernas. 18

Por linhas tortas, João Vêncio será também herói, palhaço, sábio e santo. João veio para confundir e fazer pensar, e nenhuma das suas facetas dá conta da sua personalidade e verdade. Pensamos que essa busca incessante de identidade, que força o nosso protagonista a crescer, representa uma reconstrução poética das memórias de Luandino.

16 Cf. João Vêncio: os seus amores, p. 34.

17 Idem, p.37.

18 Idem, p. 71. 


\section{Conclusão}

Nos textos analisados, pretendemos demonstrar que na obra de Luandino não temos apenas uma visão nostálgica da infância, mas sim um projecto de criação literária em função do sentido interno do tempo.

Ao assumir a imagem do velho contador de estórias, Luandino faz renascer a memória tradicional africana. Mas parece-nos que na estética de Luandino esta tradição é recriada em função de suas contradições internas permanentes, o que, em geral se encontra em autores brasileiros como José Lins do Rego, Jorge Amado, Graciliano Ramos; ou ainda, em Guimarães Rosa, a propósito da recriação linguística.

Por fim, parece-nos adequado concluir com Luandino, em seu texto A Guerra dos fazedores de chuva com os caçadores de nuvens, que, relativamente ao sentido interno do tempo como princípio absoluto da liberdade, "só as crianças podem ser ao mesmo tempo vítima, testemunha, juiz e carrasco". ${ }^{19}$

\section{Referências bibliográficas}

ANTUNES, José Freire. O factor africano: 1890-1990. Venda Nova: Bertrand Editora, 1990.

BRITO, Raimundo de Farias. O mundo interior (Ensaio sobre os dados gerais da filosofia do espírito). Estudo introdutório de Luiz Alberto Cerqueira. Lisboa: INCM, 2003.

CERQUEIRA, Luiz Alberto. O Sentido Interno do Tempo no Pensamento Brasileiro: Farias Brito. Revista Filosófica de Coimbra, Coimbra, n. 24, pp. 491-498, 2003.

CRISTÓVÃO, Fernando (dir. e coord.) Dicionário temático da lusofonia. Lisboa: Texto Editores, 2005.

GOMES, Aldónio e Fernanda Cavaca. Dicionário de autores de literaturas africanas de língua portuguesa. Lisboa: Caminho, 1997.

HOLANDA, Sérgio Buarque. Raizes do Brasil: Lisboa: Gradiva, 2000.

HUSSERL, Edmund. Lições para uma fenomenologia da consciência interna do tempo. Trad., introd. e notas de Pedro M. S. Alves. Lisboa: Imprensa Nacional-Casa da Moeda, 1994.

JUNQUEIRO, Guerra. Obras de Guerra Junqueiro. Porto: Lello \& Irmãos, s/d.

LABAN, Michel. Angola encontro com escritores. Volumes I e II. Porto: Fundação Eng. António de Almeida, s/d.

19 Cf A guerra dos fazedores de chuva com os caçadores de nuvens. 
LARANJEIRA, Pires. Literaturas africanas de expressão portuguesa. Lisboa: Universidade Aberta, 1995.

MASSAUD, Moisés. A análise literária. São Paulo: Cultrix, 1999.

MILANO, Dante. Poesias. Petrópolis: Ed. Firmo, 1994.

OLIVEIRA, Mário António F. Reler África. Coimbra: Instituto de Antropologia da Universidade de Coimbra, 1990.

PORTUGAL; Francisco Salinas. Entre o Próspero e Caliban. Galiza: Edicións Laiovento, 1999.

PROENÇA, Filho. Estilos de época na literatura: através de textos comentados. ( $7^{\mathrm{a}}$ edição) São Paulo: Editora Ática, 1983.

ROCHA, Edmundo. Angola: contribuição ao estudo da génese do nacionalismo moderno angolano. Lisboa: 2003.

ROSA, João Guimarães. Tutaméia. Rio de Janeiro: José Olympio, 1985.

TRIGO, Salvato. Ensaios de literatura comparada afro-luso-brasileira. Lisboa: Vega, s/d.

. A poética da "geração da mensagem". Porto: Brasília editora, 1979.

VENÂNCIO, José Carlos. Literatura versus sociedade. Lisboa: Veja, 1992.

VIEIRA, José Luandino. A cidade e a infância (contos). Lisboa: Caminho, 2007. . A Guerra dos fazedores de chuva com os caçadores de nuvens. Lisboa: Caminho, 2006.

. João Vêncio: os seus amores (romance) Lisboa: Caminho, 2004.

. Luuanda (estórias). Lisboa: Edições 70, 1989.

. No antigamente da vida (estórias). Lisboa: Caminho, 2005.

. Nós, os do Makulusu (romance). Lisboa: Caminho, 2004.

. Nosso Musseque (romance). Lisboa: Caminho, 2003.

. Vidas Novas (estórias). Lisboa: Caminho, 2007. 